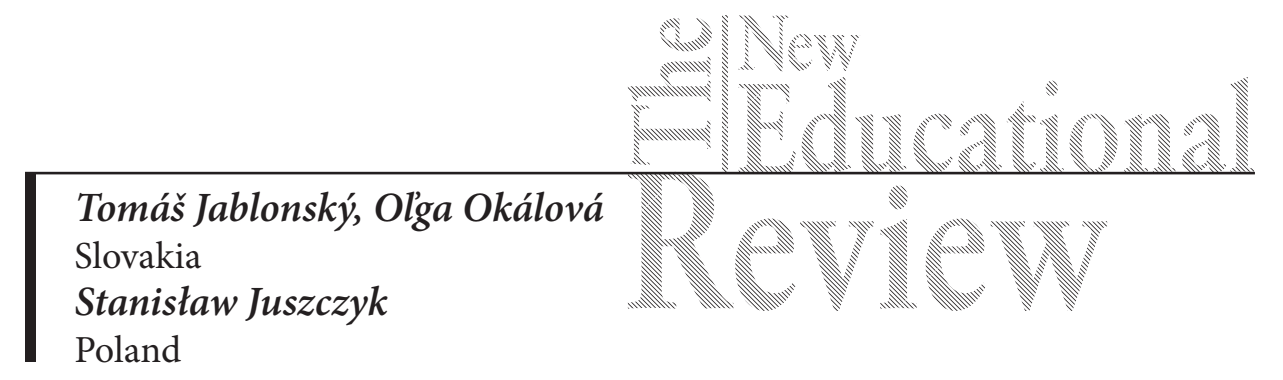

\title{
The Diagnosis of Fetal Alcohol Spectrum Disorder
}

DOI: 10.15804/tner.2015.42.4.09

\begin{abstract}
Prenatal exposure of a child to alcohol may cause Fetal Alcohol Syndrome or Fetal Alcohol Spectrum Disorder (FAS/FASD). As a result, the affected child may exhibit lower intellect, neurosensory disorders, hyperactivity, executive functions disorder, abstract thinking and behaviour disorders combined with growth disorders and facial dysmorphia. In addition, undiagnosed and untreated children may suffer from serious secondary and tertiary disabilities. The aim of this paper is to provide a research overview of practical information about FAS/FASD syndrome, a presentation of the 4-Digit Diagnostic Code method and a sample of the research results by the first Centre of Diagnosis, Treatment and Prevention of FAS in Slovakia.
\end{abstract}

Keywords: Fetal Alcohol Syndrome, Fetal Alcohol Spectrum disorder, diagnosis, treatment, prevention, Slovakia

\section{Introduction}

FAS (Q 86.0) (Fetal Alcohol Syndrome) describes a set of symptoms in the children of mothers who consumed alcohol during the pregnancy and all the symptoms, such as typical facial dysmorphia, CNS damage and a growth deficiency, are present. If only a few signs are present, these are then covered under the term FASD (Fetal Alcohol Spectrum Disorder).

Four diagnoses fall under the umbrella of FASD: FAS, partial FAS, static encephalopathy, neurobehavioral disorder. 


\section{Research Problem}

Drinking in Slovakia is high above the average. According to WHO, Slovakia is in the $19^{\text {th }}$ place for the consumption of alcohol. What is alarming is the fact that alcohol is increasingly consumed by girls. The average age of the first contact with alcohol is 10. According to the data of the Statistical Office of the Slovak Republic, the average annual consumption of pure alcohol by young people aged between 15 and 18 is almost the same (10.2 litres a year) as in adults (10.8 litres a year). Due to the immaturity of the central nervous system (CNS) and the growing incidence of binge drinking in this age group, an early onset of addiction may be expected among the girls of the reproductive age. This leads to the prenatal alcohol exposure (PAE) of the next generation. Justifications for such concerns are also confirmed by statistics, according to which up to $60 \%$ of sixteen-year-old girls attending vocational schools who regularly smoke and have experience with alcohol have already had a sexual intercourse. Some have already been engaged in sexual activity on a regular basis. Out of the girls at the same age who attend vocational schools and who do not smoke and do not drink alcohol only $26 \%$ have had a sexual intercourse. It follows that alcohol greatly speeds up the start of a sex life, brings more unwanted pregnancies and, in the end, more afflicted kids.

In the countries of Europe and North America, the treatment for the partial elimination or relief of the symptoms of FASD is known and used in practice. The systematic introduction of sensorimotor integration and executive function treatments is beneficial to the quality of life of the affected individuals and also to society. Research over the last 30 years has shown that children up to the age of 6 who have been diagnosed with FAS and with whom therapists have worked, have had good results, a higher quality of life and have been beneficial to society within their capabilities. The issue of the diagnosis, treatment and prevention for children with FAS/FASD, which is not systematically solved in Slovak society, has begun to gain in size, mainly in foster and adoptive families, where the concentration of such children is much higher.

\section{Research Focus}

In 2010-2011, after one of the authors of this paper had completed a series of training courses for educators about FAS syndrome, organised by the civic association Návrat (Return), in cooperation with Malgorzata Klecka from Poland, in 2012, at the University, a systematic scientific research activity aimed at FAS diagnosing 
started. The civic association Návrat (Return), which works with foster families and children from dysfunctional families, was looking for experts to help children who, despite the excellent care after placement in a new family, were not developing properly. In the fall of 2012, the members of the research team completed the training in the diagnosis of FAS at the University of Washington in Seattle, with Professor Susan Astley, the author of the 4-Digit Diagnostic Code manual (4DDC). In 2013, Susan Astley, with her colleague Theresa Grant, accepted an invitation to Slovakia in order to train our team. The multi-diagnostic team operating at the Education Faculty of Catholic University in Ružomberok, includes a paediatrician, a social worker, a speech therapist, a school psychologist, a special pedagogue and a therapeutic pedagogue, or physiotherapist. The diagnosing of children began in the pilot project "Support of the program dealing with children and youth with behavioural disorders", supported by the Foundation Mondi SCP, corp. However, the team members worked as volunteers, so they met for diagnostics only once a month. Thanks to the cooperation with the University of Washington, Seattle WA, and the Research Institute of Child Psychology and Pathopsychology, as well as the Nosko Health Prevention Organisation, the professional activity of the team has been continuously pursued. The team has operated as the first in Slovakia, specifically in the area of the diagnosis of children at preschool and school age with the suspicion of FAS/FASD.

\section{Research Methodology}

Given the increasing interest in the diagnosis and the assumption of the prevalence of FASD, the establishment of the centre with a systematic focus on FAS/ FASD was highly important. As a result, the Centre for Diagnosis, Treatment and Prevention of FAS has been established. In Slovakia, in contrast to the rest of the world, the diagnosis of FASD in children is underestimated. The diagnosis of FAS comprises only children with significant facial dysmorphia and the record of the alcoholism of the mother. The prevalence of FASD in Europe is estimated at the level of 1/100 of alive-born children. According to the Statistical Office of the Slovak Republic, in 2012, 55,535 children were born, which would mean that 555 children were born with FASD. We can expect a similar number of newly affected children with FAS/FASD every year. If we were to estimate undiagnosed children under 19, we would be talking about a group of 10,500 children. The majority of children diagnosed with FASD are placed in foster care. Our centre is the hope for these children and their families. Since the children with FASD syndrome have 
not got a specified diagnosis, they will not receive the special assistance required for the treatment and compensation of CNS impairment, nor the support for their integration into society. Thanks to the activities of the Centre, a network is being created, which is prepared to competently help children to cope with the consequences of their afflictions.

FAS/FASD is diagnosed on the basis of 4 criteria: exposure to alcohol during the intrauterine development, growth retardation, facial dysmorphia and brain damage in the cognitive and behavioural areas. Although these children have brain damage, there is a minimum difference in appearance from other children and their behaviour is also comparable to their peers up to preschool age. Due to sensorimotor and executive function disorders the children have the ability to communicate, yet are unable to think, perceive or respond equally. These children have similar symptoms to the children with ADHD or autism.

Early diagnosis and treatment of these disorders is essential and improves the condition of children suffering from FASD (Church and Kaltenbach, 1997). Diagnostic tools started to emerge after 1996. One of the first handbooks came from the Institute of Medicine in the USA (IOM). Separate manuals then followed, such as Canadian manual or CDC manual. The most comprehensive diagnostic system is the 4-Digit Diagnostic Code manual of FASD (Diagnostic Guide for Fetal Alcohol Spectrum Disorders - The 4-Digit Diagnostic Code (4 DDC)). In 1997 and 1999 (latest revision 2012), Astley and Clarren responded to the shortcomings in the diagnosis by creating the 4-Digit Diagnostic Code, which standardised the measurements and increased the objectivity of the diagnosis while having made provisions for the diversity in the manifestations of prenatal exposure to alcohol.

\section{Instrument and Procedures}

The following are the four diagnostic codes for the classification of FASD diagnosis:

Facial dysmorphia: measurement of the eye length (palpebral fissure length), evaluation of the philtrum and the upper lip compared to the picture of the Likert scale or the use of a photo where deviations of facial features are measured by a photographic software program.

CNS impairment: an evaluation of the structural and neurological symptoms and psychological examination by standardised tests in 7 domains: Cognitive func- 
tions (WISC, Stanford-Binet); School skills: (WRAT, WIAT, Woodcock Johnson); Social skills and adaptive behaviour (VABS, BASC, Adaptive Behavior Assessment System); Neuropsychological (Rey complex figure, NEPSY, CVLT); Sensorimotor integration (sensory profile, Bruininks-Oseretsky, VMI); Communication skills (Test narrative skills); Behaviour Rating Inventory of Executive Function (BRIEF).

Prenatal exposure to alcohol according to anamnestic data from the mother or from anamnestic data in the documentation.

Each code is evaluated depending on a 4-point Likert scale:

Code 1 indicates that the symptoms are not present.

Code 4 indicates the fully expressed classic symptoms.

By combining the codes, we obtain 256 resulting diagnoses, which are incorporated into 9 resulting diagnostic categories. During the diagnosis, we use the Diagnostic Guide for Fetal Alcohol Spectrum Disorders - The 4-Digit Diagnostic Code. Diagnostic categories: A: FAS with confirmed prenatal exposure to alcohol in the mother (FAS-AE); B: FAS prenatal exposure to alcohol in the mother is not known (FAS-AEU). Patients with partial FAS have manifestations of facial dysmorphia in combination with impaired brain development without growth deficiency. Damage to the brain in the diagnosis of FAS and partial FAS is comparable. Growth hormones do not result in an improvement of growth, because the cause is distinct C: Partial FAS with confirmed prenatal exposure to alcohol in the mother, when the child has all the symptoms of FAS except slow growth (pFAS-AE).

Other possible combinations of codes fall within the ambit of the diagnoses: D: Phenocopies of FAS (without confirmed alcohol exposure) (FASP-no AE); E: The presence of some physical symptoms along with static encephalopathy (SPFSE-AE); F: Static encephalopathy (SE-AE); G: The presence of certain physical symptoms along with neurobehavioural disorder (SPF-NBD-AE); H: Neurobehavioural disorder (NBD-AE); I-U: a combination of the previous ones; $\mathrm{V}$ : No changes were detectable, alcohol in pregnancy has not been confirmed. 


\section{Data Analysis}

Table 1. Diagnostic codes according to the Four-Digit Diagnostic Code manual

\begin{tabular}{|c|c|c|c|c|}
\hline Code & $\begin{array}{l}\text { Growth Defi- } \\
\text { ciency }\end{array}$ & $\begin{array}{l}\text { Face Dysmorphic } \\
\text { Features }\end{array}$ & $\begin{array}{l}\text { CNS Impair- } \\
\text { ment }\end{array}$ & $\begin{array}{c}\text { Confirmed Exposure to } \\
\text { Alcohol }\end{array}$ \\
\hline 4 & $\begin{array}{l}\text { Significant lagging } \\
\text { under the } 2^{\text {nd }} \\
\text { percentile }\end{array}$ & $\begin{array}{l}\text { Significant } \\
\text { All } 3 \text { features }\end{array}$ & $\begin{array}{l}\text { Definite } \\
\text { Structural and } \\
\text { Neurological } \\
\end{array}$ & $\begin{array}{l}\text { High-risk drinking during } \\
\text { pregnancy }\end{array}$ \\
\hline 3 & $\begin{array}{l}\text { Moderate } \\
3-6 \text { percentile }\end{array}$ & $\begin{array}{l}\text { Moderate } \\
2.5 \text { features }\end{array}$ & $\begin{array}{l}\text { Probable } \\
\text { dysfunction }\end{array}$ & $\begin{array}{l}\text { Mother drank occasionally } \\
\text { during the pregnancy }\end{array}$ \\
\hline 2 & $\begin{array}{l}\text { Mild } \\
6-10 \text { percentile }\end{array}$ & $\begin{array}{l}\text { Mild } \\
1-2 \text { features }\end{array}$ & $\begin{array}{l}\text { Possible dys- } \\
\text { function }\end{array}$ & $\begin{array}{l}\text { We do not have information } \\
\text { about the mother's drinking }\end{array}$ \\
\hline 1 & $\begin{array}{l}\text { None } \\
>10 \text { percentile }\end{array}$ & Without afflictions & Unlikely & $\begin{array}{l}\text { Mother did not drink bever- } \\
\text { ages containing alcohol }\end{array}$ \\
\hline
\end{tabular}

Source: Astley, 2004.

The positive aspect of the system is the objective measurement that has replaced the previous subjective approach. Growth is objectified thanks to the growth charts divided into the percentiles by age and gender. An evaluation of face dysmorphia is compared to a Likert pictorial 5-point scale. Changes in the centre of the face correlate with the damage to the same part of the face in experimental animals with prenatal exposure to alcohol on the $19^{\text {th }}$ up to the $21^{\text {st }}$ day of gestation. This leads to disturbances in the development of the forebrain. We measure the plapebral fissure length by hand or with the use of photographic software using the Z-score which is adjusted to age and ethnicity. Further dysmorphic symptoms may be present, however, they are not specific to FAS. Genetic testing is also important for the exclusion of possible similar genetic syndromes. When coding CNS impairment, damage to the structures of the brain and its functions is taken into account. Furthermore, other prenatal factors are taken into account relating to genetic damage, inappropriate prenatal care or postnatal care, e.g., the placement of children in several foster families or other institutions, adverse life situations, premature birth. Two "old-new" concepts are here specified:

Neurobehavioural disorder is defined as a cognitive-emotionally-socially-impaired child, whose problems could also be caused by other factors, such as genetic changes, toxic substances, and problems during the perinatal period.

Static encephalopathy is defined as significant damage to the structures of the CNS or its functions manifested in the cognitive, emotional and social areas.

The weak aspect of the 4-Digit Diagnostic Code lies in discrepancy between the assessment of the facial dysmorphia and a consensus on the diagnostic codes. 
In addition, the criteria are quite numerous. A revision of the 2004 Likert scale according to racial nationality has brought about more accurate documentation of brain function domains.

\section{Research Results: The measured 4 codes among a selected sample of Slovak children}

Up till now, the Centre of Diagnosis, Treatment and Prevention of FAS has diagnosed 23 clients using the 4-Digit Diagnostic Code method. The children were under 15 years of age. Out of those we chose 19 records.

The youngest client was an infant of 6 months of age, in whom it was already possible to establish the diagnosis of FAS.

Table 2. The measured 4 codes in a selected sample of clients from the Centre of Diagnosis, Treatment and Prevention of FAS

\begin{tabular}{|c|c|c|c|c|}
\hline $\begin{array}{l}\text { Age at the time of } \\
\text { the diagnosis }\end{array}$ & $\begin{array}{l}\text { The form of care } \\
\text { during the diag- } \\
\text { nosis }\end{array}$ & $\begin{array}{c}\text { The } \\
\text { presence } \\
\text { of CAN } \\
\text { syndrome }\end{array}$ & $\begin{array}{l}\text { Code/category/ } \\
\text { diagnosis }\end{array}$ & $\begin{array}{c}\text { Presence } \\
\text { of secondary/ } \\
\text { tertiary mani- } \\
\text { festations }\end{array}$ \\
\hline 6 months & Children's home & Yes & 3444/A/FAS-AE & No \\
\hline 1 year, 2 months & Foster Care & Yes & 3224/G/SPF-NBD-AE & No \\
\hline 3 years, 2 months & Adoption & Yes & 1323/G/ SPF-NBD-AE & Yes \\
\hline 4 years, 3 months & Adoption & Yes & 3243/E/ SPF-SE-AE & Yes \\
\hline 4 years, 4 months & Foster Care & Yes & 1344/ C/pFAS-AE & Yes \\
\hline 4 years, 6 months & Foster Care & Yes & 4444/A/FAS-AE & Yes \\
\hline 4 years, 8 months & Adoption & Yes & $1433 / \mathrm{C} / \mathrm{pFAS}-\mathrm{AE}$ & Yes \\
\hline 5 years, 3 months & Foster Care & Yes & 4443/A/FAS-AE & Yes \\
\hline 5 years, 4 months & Foster Care & Yes & $1224 / \mathrm{H} / \mathrm{NBD}-\mathrm{AE}$ & Yes \\
\hline 6 years 2 months & Foster Care & Yes & 2244/ F/SE-AE & Yes \\
\hline 7 years, 4 months & Biological family & Yes & 1223/H/NBD-AE & Yes \\
\hline 7 years, 6 months & Adoption & Yes & 1424/G/ SPF-NBD-AE & Yes \\
\hline 7 years, 8 months & $\begin{array}{l}\text { Children's home/ } \\
\text { Professional family }\end{array}$ & Yes & 1243/ F/SE-AE & Yes \\
\hline 7 years, 9 months & Foster Care & Yes & 1234/F/SE-AE & Yes \\
\hline 8 years, 2 months & Adoption & Yes & 1232/L/SE-AEU & Yes \\
\hline 8 years, 7 months & Foster Care & Yes & 1234/ F/SE-AE & Yes \\
\hline
\end{tabular}




\begin{tabular}{llccc}
\hline $\begin{array}{c}\text { Age at the time of } \\
\text { the diagnosis }\end{array}$ & $\begin{array}{c}\text { The form of care } \\
\text { during the diag- } \\
\text { nosis }\end{array}$ & $\begin{array}{c}\text { The } \\
\text { presence } \\
\text { of CAN } \\
\text { syndrome }\end{array}$ & $\begin{array}{c}\text { Code/category/ } \\
\text { diagnosis }\end{array}$ & $\begin{array}{c}\text { Presence } \\
\text { of secondary/ } \\
\text { tertiary mani- } \\
\text { festations }\end{array}$ \\
\hline 10 years, 4 months & Adoption & Yes & 2234/ F/SE-AE & Yes \\
\hline 13 years, 7 months & Foster Care & Yes & 2324/G/ SPF-NBD-AE & Yes \\
\hline $\begin{array}{l}14 \text { years, } 11 \\
\text { months }\end{array}$ & $\begin{array}{l}\text { Substitute personal } \\
\text { care }\end{array}$ & Yes & $2234 /$ F/SE-AE & Yes \\
\hline
\end{tabular}

\section{Discussion}

We have measured severe afflictions predominantly with clients up to five years of age. Early diagnosis increases the success of intervention and protection before secondary and tertiary afflictions develop. The bulk of the clients aged from 6 to 14 were diagnosed with "static encephalopathy". During the diagnosis, only one client was placed in his biological family, the others lived in substitute care, of which the most common form was foster care. In all of the clients it was possible to prove CAN syndrome. In only two clients, aged 6 months and 14 months, the presence of secondary and tertiary afflictions was not recorded. During the diagnosis of CNS, standardised tests for the Slovak population were used: Iq tests - WISC-III, Stanford-Binet, T-228 Test of the level of intellectual abilities - TURS, IDS - Intelligence and developmental scale for children from 5 to 10; Learning disorders - Woodcock Johnson, T-239 Diagnosis of specific learning disorders, T-41 Trail Making Test - TMT, T-92 Bender - Geštalt test, T-111 Battery of neuropsychological tests for number processing and calculation in children ZAREKI, T-122 Tests of mathematical abilities, T-269 Dynamic test of the latent learning abilities of children aged 6-8, Attention test d2-R; Adaptive behaviour/ social skills - T - 18 A questionnaire on the behaviour of preschool children, T-85 The scale of classic fear, social-situational anxiety and examination fever KSAT, T-98 A questionnaire on social segmentation, T-100 Children screening, T-106 CATO, T-112 Children's Manifest Anxiety Scale - CMAS, T-161 State-Trait Anxiety Inventory - STAI; Neuropsychological examinations - T-111 Battery of neuropsychological tests for number processing and calculation in children - ZAREKI, T-65 Rey-Osterrieth Complex Figure test - TKF; Sensory integration -Bruininks-Oseretsky Test of Motor Proficiency, MABC-2-The Movement Assessment Battery for Children; Speech/Social Communication - TEKOS - Test 
of Communication Behaviour, Heidelberg Speech Development Test (H-S-E-T); Executive functions - WCST - Wisconsin Card Sorting Test, BRIEF - Behavior Rating Inventory of Executive Function in children.

Since our set mainly represents primary school pupils, the reason for the diagnosis was to adequately integrate the children within the education system of Slovakia. The focal point of the caregivers' expectations was the creation of the social environment criteria of a child with FAS/FASD related to his community, adaptability and utility. We are processing more detailed scientific results about diagnostic recommendations in a separate study.

\section{Conclusions and recommendations for practice}

Individuals with FASD have numerous secondary and tertiary afflictions, which are extensions of primary problems and are potentially preventable. These afflictions arise in children due to an inappropriate approach and the lack of a proper diagnosis. The afflictions are manifest in problems at school, psychiatric problems, unreasonable sexual behaviour, alcohol and drug addiction, conditional sentencing and punishment. Streissguthová et al. 19, 26 found that an early diagnosis, ideally before the age of 5 , is the strongest correlation factor for the reduction and prevention of secondary afflictions. An early diagnosis prepares the family and the child for difficulties during adolescence and allows for support through adequate social benefits. A young person with CNS impairment may have a greater chance for his/ her independence and in the end, fewer problems in applying himself/herself in adulthood. With the availability of special education, the child may have better conditions for the development of adequate self-esteem. An early diagnosis is also a marker of the mother's mental health. An effective treatment for mothers reduces the risk of the removal of the child from the mother, lowers the risk of an impact on other offspring and allows for intervention in the case of other affected siblings.

Obtaining the data from the mother's medical history seems to be challenging in Slovakia. If the biological mother is not known, we must rely on indirect information. When determining the medical history directly from the mother, the data is unreliable, often underestimated. Research by Streissguthova (2000) showed that when determining a diagnosis, the focus should not only be on physical changes, but also on the diagnosis of CNS deficits. An additional diagnostic dilemma is the ethnic differences in the white and Roma populations. The fact that Roma people are generally smaller results in a false positive code for the delayed growth and smaller head circumference. 
In order to establish a FAS diagnosis, many social and medical obstacles have to be overcome. The level of knowledge about FAS within the European continent among paediatricians and school psychologists is alarmingly low. The opinions of gynaecologists in the EU are inconsistent and they often do not warn pregnant women of the harmfulness of alcohol. Gynaecologists are not trained on how to take care of pregnant alcoholics. Even when paediatricians know about alcohol consumption during pregnancy and suspect FAS, many of these children are not sent for FAS diagnosis because of the stigma and the fear of the biological family's reaction and resistance.

A final problem is the inconsistency of the international classifications. In Slovakia, the diagnosis of FASD is new in terms of the multidisciplinary approach. Due to the rising interest of the target group in this type of diagnosis and the need for new forms of treatment and prevention in the area of FAS/FASD among the children at preschool and school age, a diagnostic team was formed in 2012 at the Pedagogical Faculty, Catholic University, in Ružomberok, as a first step in the diagnostics of FAS/FASD. The Centre of Diagnosis, Treatment and Prevention of FAS at the Catholic University Faculty of Education provides comprehensive diagnostic, counselling, rehabilitation, preventive, methodological, educational, research, and development activities, including a set of special pedagogical interventions for children diagnosed with FAS/FASD, in order to reach the optimal development of their personality and social integration. The centre is set up according to the American model of the clinic at the University of Washington in Seattle, which is run within the Centre on Human Development \& Disability and is called FAS DNP (Fetal Alcohol Syndrome Diagnostic \& Prevention Network). Because for children with FASD accurate diagnosis is the first and most important step that changes the attitude of parents and teachers in order to seek help, the idea of our centre is to create a network of diagnostic and therapeutic centres.

\section{References}

Abel, E.E.(1998), Fetal alcohol syndrome The 'American Paradox', Alcohol \& Alcoholism 33: 3, 195-201.

Astley, S.J. (2004). Diagnostic Guide for FASD. Diagnostic Guide for Fetal Alcohol Spectrum Disorders: The 4-Digit Diagnostic Code. Third Edition.

Astley, S.J. (2006). Comparison of the 4-digit Diagnostic Code and the Hoyme Diagnostic Guidelines for Fetal Alcohol Spectrum Disorders. Pediatrics 118:1532-45.

Church, M.W., Kaltenbach, J.A. (1997). Hearing, Speech, Language, and Vestibular Disorders in the Fetal Alcohol Syndrome: A Literature Review. Alcoholism: Clinical and Experimental Research, 21: 495-512. 
Fetal Alcohol Spectrum Disorders Fact Sheet, NIH, October 2010.

Grant, T.M.,Huggins, J.E., Sampsons, P.D., Ernst, C.C., Barr, H.M., Streissguth, A.P. Alcohol Use Prior to and During Pregnancy in Western Washington, 1989-2004: Implications for Preventing Fetal Alcohol Spectrum Disorders, Am J Obstet Gynecol. Mar 2009; 200(3): 278.e1-278.e8

Lemoine, P., Harousseau, H., Borteyru, J.P., And Menuet, J.C. (1968). Les enfants de parents alcooliques: Anomalies observées à propos de 127 cas (Children of alcoholic parents-observed anomalies: discussion of 127 cases). Quest Med 21:476-482.

Národná správa o ludskom rozvoji (National Report on Human Development) SR 2001-2002: 55.

Okruhlica, L. (2012). NegatívnedopadynadmernéhopitianaSlovensku (The negative impact of excessive drinking in Slovakia).

Streissguth, A.P.,Bookstein, F.L.,Baar, H.m.,Sampson, P.D., O’malley, K. (2004). Developmental and Behavioral Pediatrics 25: 4,228-238.

Streissguth, A.P., O'malley K. (2000). Neuropsychiatric implications and long-term consequences of fetal alcohol spectrum disorders. SeminClin Neuropsychiatry; 5:177-90.

Central Office of Labour, Social Affairs and Family ( 2014)

http://www.upsvar.sk/detske-domovy-a-ine-zariadenia/detske-domovy/vybrane-statisticke-ukazovatele.html?page_id=130708 